\title{
Healthcare Use in Patients With Cardiovascular Disease and Depressive Symptoms - The Impact of Internet-Delivered Cognitive Behavioural Therapy. A Secondary Analysis of a RCT
}

\section{Ghassan Mourad ( $\nabla$ ghassan.mourad@liu.se)}

Department of Health, Medicine and Caring Sciences, Linköping University, Linköping

\section{Johan Lundgren}

Department of Health, Medicine and Caring Sciences, Linköping University, Linköping

\section{Gerhard Andersson}

Department of Behavioural Sciences and Learning and Department of Biomedical and Clinical Sciences. Linköping University, Linköping

\section{Mats Westas Klompstra}

Department of Health, Medicine and Caring Sciences, Linköping University, Linköping

\section{Peter Johansson}

Department of Health, Medicine and Caring Sciences and Department of internal medicine, Linköping University, Linköping

\section{Research Article}

Keywords: Cardiovascular disease, Depressive symptoms, Healthcare use, hospital admissions, outpatient services, Internet-delivered cognitive behavioural therapy.

Posted Date: September 14th, 2021

DOI: https://doi.org/10.21203/rs.3.rs-858227/v1

License: (c) (1) This work is licensed under a Creative Commons Attribution 4.0 International License. Read Full License 


\section{Abstract}

Background: Depressive symptoms in patients with cardiovascular disease (CVD) can lead to increased healthcare use and cause an economical burden for society. Thus, interventions aiming to decrease depressive symptoms in these patients could reduce the use of healthcare services. In a previous study we reported that a 9-week internet-delivered cognitive behavioural therapy (iCBT) program $(n=72)$ compared to an online discussion forum (ODF) $(n=72)$ had moderate to large effect on depression in CVD outpatients. However, the associations between healthcare use and depressive symptoms were not reported in that study. The aim of this study was to describe and compare the effect of iCBT compared to ODF regarding healthcare use and to identify factors impacting healthcare use in these groups.

Methods: Secondary analysis of a RCT. Data on healthcare use (including outpatient clinic/primary care contacts and hospital admissions) were retrieved from care data registries in five hospitals in Southeastern Sweden. Patients were predominantly males in both groups with a mean age of $61 \pm 13$ and $64 \pm 12$ years in iCBT and ODF respectively.

Results: The year before the intervention, the iCBT group had a mean of 31 outpatient contacts per patient compared with 21 contacts the year after. The corresponding numbers for the ODF group were 37 and 25 . The decrease was $32 \%$ in both groups and did not differ significantly between the groups.

Regarding hospital admissions, the iCBT group had 0.8 admissions per patient the year before and 0.6 the year after the intervention, i.e. a decrease by $25 \%$, whereas the ODF group had 1.1 and 0.6 admissions respectively, i.e. a decrease by $45 \%$. The difference was not significant between the groups.

Improvement in depressive symptoms post intervention was significantly associated with a decrease in number of outpatient contacts in the iCBT group. In the ODF group, better mental health-related quality of life post intervention was significantly associated with a decrease in number of hospital admissions.

Conclusions: Reduced depressive symptom scores following intervention were associated with lower outpatient service use, but iCBT was not superior compared to ODF in decreasing healthcare use.

Trial registration: The study was registered at ClinicalTrials.gov, NCT02778074.

\section{Highlights}

- Patients with CVD use outpatient healthcare services to a great extent

- Both iCBT and online discussion forum gave a decrease in healthcare use by one-third

- Reduced depressive symptom scores were associated with lower outpatient service use

- iCBT was not superior to online discussion forum in decreasing healthcare use

\section{Introduction}


Depression is common (20-40\%) in patients with cardiovascular disease (CVD) and significantly worsens the health of the patients (1). Patients with CVD and depression have a shorter life expectancy (2) and higher risk of non-fatal cardiac events, e.g. re-hospitalization than CVD patients without depression (3). Thus, depression adds an extra burden for patients in addition to the consequences of CVD.

Depression also has a societal impact. Studies show that depression increases the use of healthcare services, even after adjusting for somatic morbidity (4). This is also the case for patients with various chronic somatic diseases $(5,6)$. In a study focusing on CVD patients, depression was found to be a significant predictor of increased healthcare costs (7). These costs were related to healthcare use in almost all healthcare sectors, including acute inpatient care, chronic care, physician costs and medications. Palacios et al (8) investigated depression and healthcare costs in outpatients with coronary heart disease over a three-year period. They found that those with worsening or chronic depressive symptoms had over 2 times higher costs than patients with no depressive symptoms. In addition, patients with worsening or chronic depressive symptoms that were detected and treated had lower costs compared to those that were undetected and untreated (8). Depressed CVD patients experience poorer health-related quality of life (HRQoL) (9), but although there is a strong relationship between depressive symptoms and HRQoL, HRQoL mirrors a broader perspective of the CVD patient's health than the mental aspects, such as depressive symptoms. This suggests that interventions aiming to decrease depression in patients with CVD, particularly outpatients who have worsening or chronic depressive symptoms, also could improve HRQoL, reduce the burden for the patient, as well as the costs for society. Palacios et al (8) emphasized that such interventions should target outpatients rather than those hospitalized or newly discharged. Furthermore, such interventions should focus more on the effects on depression and healthcare costs than the impact on adverse cardiac events or prognosis.

Internet-based cognitive behavioural therapy (iCBT) constitutes a new promising intervention that can decrease depressive symptoms in patients without CVD (10). Regarding the health-economic benefits of iCBT for depression in non-CVD populations, Donker et al (11) were not able to perform a meta-analysis of 16 iCBT studies as the studies used different methods in their economic evaluation. The authors however stated that iCBT appeared to be cost-effective, especially the guided intervention modalities. In a recent paper, Kolovos et al (12) were able to evaluate cost-effectiveness in a meta-analysis of five iCBT studies on depression. Surprisingly, they reported similar cost-effectiveness of iCBT compared to control conditions, such as care as usual and psychoeducation or care as usual and a self-help booklet or a waiting list. The authors commented that the five studies only constituted a small fraction of the number of randomised controlled iCBT studies published (12). Thus, there is a knowledge gap regarding healtheconomic evaluations of iCBT and particularly the impact of iCBT on healthcare use.

The number of iCBT studies on patients with chronic somatic illnesses, such as those with CVD, is still limited both regarding the effect on depression and health-economy $(13,14)$. In patients with chronic somatic conditions and depression, the impact of iCBT on healthcare use is especially interesting since these patients have increased healthcare use. Recently we reported that a nine-week iCBT program 
compared to an online discussion forum (ODF) had moderate to large effects on depressive symptoms and HRQoL in CVD outpatients (15). The associations between healthcare use and depressive symptoms were not reported in that study, and we now therefore aim to describe and compare the effect of iCBT compared to ODF regarding healthcare use and to identify factors impacting healthcare use in these groups.

\section{Methods}

\section{Setting and subjects}

The present study is a secondary analysis of a randomized controlled trial (RCT) reporting a detailed description of healthcare use and differences between CVD patients enrolled to either iCBT or ODF. The primary study with the primary aim to reduce depressive symptoms has been described in detail elsewhere (15). Briefly, invitations were sent by post to all patients who had been in contact with the medical or cardiac clinics at five hospitals in Southeastern Sweden. After screening for depressive symptoms (i.e. Patient Health Questionnaire-9 (PHQ-9) score $\geq 5$ ), 144 patients who fulfilled the criteria (e.g. age above 18 years, and not being hospitalized the past four weeks prior to inclusion) and consented to participate were allocated to nine weeks of iCBT $(n=72)$ or ODF $(n=72)$. Of the 72 patients in the ODF group, 27 (38\%) received iCBT after study completion. The iCBT program included one goal setting module, two psycho-education modules, one problem-solving module, two behavioural activation modules and a summary module. All modules included homework assignments and written feedback was provided on each assignment from a study nurse. A total of $60 \%$ of those in the iCBT group completed all seven modules, and $82 \%$ completed at least 4 modules. The ODF consisted of nine discussion topics moderated by a nurse. In this group, $27 \%$ were active at least nine times during the nine weeks of the intervention.

\section{Data collection}

\section{Depressive symptoms and health-related quality of life}

Data regarding depressive symptoms and HRQoL were obtained at baseline and at 9-weeks follow-up in the main RCT study (15).

Depressive symptoms were measured using PHQ-9, which consists of nine items that are rated on a fourpoint scale from (not at all, several days, more than half the days, nearly every day) and with a summary score ranging from 0 to 27 (16). Scores between 5-9 indicate mild depressive symptoms; scores of 1014 suggest moderate depressive symptoms and scores of 15 and above indicate severe depressive symptoms. The PHQ-9 has demonstrated good psychometric properties $(16,17)$, also in patients with CVD (i.e. heart failure) (18). The PHQ-9 has also proved to be valid in the computerized format (19).

The Short Form 12 (SF-12) (20) and the EuroQol Visual Analogue Scale EQ-VAS (21) were used to assess HRQoL. The SF-12 comprises 12 items that originates from the longer instrument Short Form-36 (SF-36) 
(20), and has been used in a wide range of studies and populations, including patients with CVD (22). The SF-12 is divided into a physical component score (PCS) and a mental component score (MCS). The EQ-VAS is a visual analogue scale that ranges between 0 (worst health you can imagine) and 100 (best health you can imagine).

\section{Healthcare use}

Data on healthcare use including outpatient clinic and primary care contacts, and hospital admissions were collected from care data registries in Region Östergötland, Region Jönköping County and Region Kalmar County, Sweden. The retrieved data comprised all healthcare use, i.e., all healthcare contacts within primary care, outpatient clinics and hospital care, one year prior to study start and one year after end of the study, which lasted for 9 weeks. Data on healthcare use were not possible to obtain for six participants. This was because they were residents in other regions, despite receiving treatment for CVD in any of the four recruitment hospitals and thereby included in the RCT.

\section{Statistical analysis}

Data on healthcare use were summed for each participant and divided into contacts and admissions one year before study start (i.e., the day before study start and one year back), and one year after end of study (i.e., the day after study completion and one year forward). Length of hospital stay was reported in days. Due to different registration procedures at the different hospitals, where some reported the exact time for the hospital stay and some only reported the dates, each admission is reported as at least one day even when it was not 24 hours.

Demographic data and healthcare use were presented using numbers, percentages, mean values, and standard deviations. Differences in demographic data between the iCBT and ODF groups were analyzed using Chi-Square test for categorical variables and Student's $t$-test for continuous variables. Student's $t$ test was also used to compare the iCBT and ODF groups with regard to healthcare use. For comparison within groups between the year prior to and the year post intervention, paired Samples $t$-test was used.

Pearson correlations as well as multiple linear regression were used to explore possible associations between change in healthcare use and depressive symptoms and HRQoL. All variables (See Table 1 and Table 2) that correlated significantly with change in healthcare use were used as covariates in the linear regression analysis (i.e., sex, marital status, occupational status, financial situation, and number of comorbidities). However, since change scores for depressive symptoms and HRQoL do not automatically indicate a significant improvement in depressive symptoms and HRQoL (for example, a patient can have decreased PHQ-9 scores from 25 to 20, but still having a high level of depressive symptoms), we used the follow-up scores for depressive symptoms and HRQoL as variables in the regression analysis.

The independent variables used were all entered in the regression model. The associations were classified as weak with beta values of $0.10-0.30$, moderate with beta values of $0.31-0.50$, and as strong with beta values above 0.50 . All analyses in the present study are based on the collected data, without 
imputation. The level of $p<.05$ was set for significance. The IBM SPSS version 25.0 was used for data analysis. 
Table 1

Demographic data of patients randomized to Internet-delivered cognitive behavioural therapy (iCBT) or online discussion forum (ODF).

\begin{tabular}{|c|c|c|}
\hline & iCBT $(n=72)$ & ODF $(n=72)$ \\
\hline Sex, n (\%) ${ }^{a}$ & $47(65)$ & $42(58)$ \\
\hline Male & $25(35)$ & $30(42)$ \\
\hline \multicolumn{3}{|l|}{ Female } \\
\hline Age, mean $(S D)^{a}$ & $61(13)$ & $64(12)$ \\
\hline Educational level, n (\%) ${ }^{a}$ & $7(10)$ & $12(17)$ \\
\hline Elementary & $16(22)$ & $21(29)$ \\
\hline Upper secondary/high school & $12(17)$ & $6(8)$ \\
\hline Post-secondary vocational education & $37(51)$ & $33(46)$ \\
\hline \multicolumn{3}{|l|}{ College/university } \\
\hline Work status, n (\%) ${ }^{a}$ & $26(36)$ & $18(25)$ \\
\hline Working & $8(11)$ & $10(14)$ \\
\hline Sick leave/disability pension & $32(44)$ & $36(50)$ \\
\hline Retired & $6(8)$ & $8(11)$ \\
\hline \multicolumn{3}{|l|}{ Other } \\
\hline Marital status, $\mathrm{n}(\%)^{\mathrm{a}}$ & $53(74)$ & $53(74)$ \\
\hline Married/cohabiting & $19(26)$ & $19(26)$ \\
\hline \multicolumn{3}{|l|}{ Living alone } \\
\hline Financial Situation, n (\%) ${ }^{\mathrm{a}}$ & $10(14)$ & $11(15)$ \\
\hline Very good & $49(68$ & $45(63)$ \\
\hline Good & $10(14)$ & $14(19)$ \\
\hline Problematic & $3(4)$ & $2(3)$ \\
\hline Very problematic & & \\
\hline
\end{tabular}




\begin{tabular}{|c|c|c|}
\hline & iCBT $(n=72)$ & ODF $(n=72)$ \\
\hline Smoking, $\mathrm{n}(\%)^{\mathrm{a}}$ & $33(46)$ & $36(50)$ \\
\hline Never & $37(51)$ & $33(46)$ \\
\hline Ex-smoker & $2(3)$ & $3(4)$ \\
\hline \multicolumn{3}{|l|}{ Smoker } \\
\hline Alcohol, n (\%) & $51(71)$ & $58(80)$ \\
\hline $0-4$ units per week & $17(24)$ & $10(14)$ \\
\hline 5-9 units per week & $3(4)$ & $4(6)$ \\
\hline $10-14$ units per week & $1(1)$ & $0(0)$ \\
\hline \multicolumn{3}{|l|}{15 or more units per week } \\
\hline Comorbidities, $\mathrm{n}(\%)^{\mathrm{a}}$ & $34(47)$ & $29(40)$ \\
\hline Ischemic heart disease & $40(56)$ & $41(57)$ \\
\hline Atrial fibrillation & $18(25)$ & $20(28)$ \\
\hline Heart failure & $36(50)$ & $40(56)$ \\
\hline Hypertension & $8(11)$ & $13(18)$ \\
\hline Diabetes & $7(10)$ & $8(11)$ \\
\hline Pulmonary disease & $9(13)$ & 10(14) \\
\hline Stroke and/or TIA & $3(4)$ & $2(3)$ \\
\hline Renal disease & $7(10)$ & $9(13)$ \\
\hline Cancer & $4(6)$ & $8(11)$ \\
\hline \multicolumn{3}{|l|}{ Other psychiatric disorder } \\
\hline Co-morbidities (3 or more), n (\%) & $10(14)$ & $13(18)$ \\
\hline \multicolumn{3}{|l|}{$\mathrm{TIA}=$ Transitory Ischemic Attack } \\
\hline${ }^{\mathrm{a}}$ No significant differences were & etween the & \\
\hline
\end{tabular}


Table 2

Depressive symptom and HRQoL scores at baseline and 9-week follow-up in the patients randomized to Internet-delivered cognitive behavioural therapy (iCBT) or online discussion forum (ODF).

\begin{tabular}{|llllll|}
\hline & \multicolumn{2}{l}{ iCBT $(\mathbf{n = 7 2 )}$} & p-value \\
\cline { 2 - 5 } & Baseline & 9-weeks & Baseline & 9-weeks & \\
& mean (SD) & mean (SD) & mean (SD) & mean (SD) & \\
\hline PHQ-9 & $10.7(4.5)$ & $6.6(4.8$ & $10.2(5.1)$ & $8.7(4.6)$ & $<.001$ \\
\hline EQ-VAS & $53.3(20.0)$ & $65.1(21.8)$ & $57.2(18.1)$ & $57.0(22.1)$ & $<.001$ \\
\hline PCS12 & $39.7(10.1)$ & $41.7(10.6)$ & $37.6(11.0)$ & $37.8(11.6)$ & .078 \\
\hline MCS12 & $35.9(9.2)$ & $43.4(11.0)$ & $36.4(10.0)$ & $38.0(10.5)$ & $<.001$ \\
\hline
\end{tabular}

\section{Results}

\section{Study participants}

A detailed presentation of the study participants is presented in the main publication (15). Shortly described, out of 272 patients who registered their interest in study participation, 144 fulfilled the inclusion criteria and were randomised to either iCBT $(n=72)$ or ODF $(n=72)$, see Table 1 . The iCBT group had a mean age of $61 \pm 13$ years compared to $64 \pm 12$ years in the ODF group. Both iCBT and ODF groups consisted of more men ( $65 \%$ and $58 \%$ ) than women (35\% and $42 \%)$. About half of both groups had a college/university degree, and three out of four were married or cohabiting. There were no significant differences between the two groups regarding any of the demographic variables.

Depressive symptoms and HRQoL scores at baseline and 9-weeks follow-up have been presented in the main publication (15), see Table 2.

\section{Healthcare use in patients randomized to iCBT or ODF Outpatient clinic and/or primary care contacts}

Table 3 shows the number of outpatient clinic and/or primary care contacts in the iCBT and ODF groups one year prior to and one year post intervention. In the iCBT group, there was a decrease per patient from 31 contacts the year prior to intervention to 21 contacts the year after. The corresponding numbers of contacts were 37 and 25 contacts for the ODF group. This gave a decrease by $32 \%$ in both groups. Thus, no significant between-group differences were found in the number of outpatient clinic and/or primary care contacts the year post intervention compared to the year prior to intervention. Most outpatient clinic/primary care contacts were made to physicians, nurses and rehabilitation staff (i.e., physiotherapists and occupational therapists), see Fig. 1. There were no significant differences between 
the groups in any of the types of contacts. Within-group analysis revealed a significant $(p<.001)$ decrease between the years in in both groups.

Table 3

Outpatient clinic and/or primary care contacts in patients randomized to internet-delivered cognitive behavioural therapy or online discussion forum

\begin{tabular}{|llll|}
\hline & $\begin{array}{l}\text { iCBT } \\
(\mathbf{n =} \\
70)\end{array}$ & $\begin{array}{l}\text { ODF } \\
(\mathbf{n =} \\
68)\end{array}$ & $\begin{array}{l}\text { Between group differences prior to and } \\
\text { post intervention, p-value }\end{array}$ \\
\hline $\begin{array}{l}\text { Number of contacts per patient, mean } \\
\text { (SD) }\end{array}$ & 31 & 37 & .261 \\
$\begin{array}{l}1 \text { year prior to intervention } \\
(31)\end{array}$ & $\begin{array}{l}(31) \\
1 \text { year post intervention }\end{array}$ & $\begin{array}{l}21 \\
(25)\end{array}$ & $\begin{array}{l}25 \\
(23)\end{array}$ \\
$\begin{array}{l}\text { Within group differences prior to and } \\
\text { post intervention, p-value }\end{array}$ & $<.001$ & $<.001$ \\
\hline
\end{tabular}

\section{Hospital admissions and length of stay}

Table 4 presents the number of hospital admissions in the iCBT and ODF groups one year prior to and one year post intervention. In the iCBT group, there was a decrease per patient from 0.8 hospital admissions the year prior to intervention to 0.6 admissions the year after. The ODF group had a decrease from 1.1 to 0.6 admissions between the years. The iCBT group had a decrease by $25 \%$, compared to $45 \%$ in the ODF group. However, this was not significant between the groups. The decrease in admissions was significant in the ODF group $(p=.03)$, but not I the iCBT group.

Table 4

Hospital admissions in patients randomized to internet-delivered cognitive behavioural therapy or online discussion forum

\begin{tabular}{|c|c|c|c|}
\hline & $\begin{array}{l}\text { iCBT } \\
(n== \\
70)\end{array}$ & $\begin{array}{l}\text { ODF } \\
(n== \\
68)\end{array}$ & $\begin{array}{l}\text { Between group differences prior to and } \\
\text { post intervention, P-value }\end{array}$ \\
\hline $\begin{array}{l}\text { Number of admissions per patient, } \\
\text { mean (SD) }\end{array}$ & $\begin{array}{l}0.8 \\
(1.5)\end{array}$ & $\begin{array}{l}1.1 \\
(1.6)\end{array}$ & \multirow{2}{*}{$\begin{array}{l}.270 \\
.883\end{array}$} \\
\hline $\begin{array}{l}1 \text { year prior to intervention } \\
1 \text { year post intervention }\end{array}$ & $\begin{array}{l}0.6 \\
(1.5)\end{array}$ & $\begin{array}{l}0.6 \\
(2.2)\end{array}$ & \\
\hline $\begin{array}{l}\text { Within group differences prior to and } \\
\text { post intervention, p-value }\end{array}$ & .307 & .030 & \\
\hline
\end{tabular}

In the iCBT group, the length of stay decreased by $13 \%$, i.e. a change from 2.4 days to 2.1 days per patient (Table 5), whereas in the ODF group, there was a decrease by $56 \%$, i.e. a change from 4.1 days to 1.7 days. The difference between the groups was anyhow not significant. 
Table 5

Length of stay in days in patients randomized to internet-delivered cognitive behavioural therapy or online discussion forum

\begin{tabular}{|c|c|c|c|}
\hline & $\begin{array}{l}\text { iCBT } \\
(n= \\
70)\end{array}$ & $\begin{array}{l}\text { ODF } \\
(n= \\
68)\end{array}$ & $\begin{array}{l}\text { Between group differences prior to and } \\
\text { post intervention, P-value }\end{array}$ \\
\hline $\begin{array}{l}\text { Length of stay in days per patient, } \\
\text { mean (SD) }\end{array}$ & $\begin{array}{l}2.4 \\
(5.9)\end{array}$ & $\begin{array}{l}4.1 \\
(8.9)\end{array}$ & \multirow{2}{*}{$\begin{array}{l}.173 \\
.776\end{array}$} \\
\hline $\begin{array}{l}1 \text { year prior to intervention } \\
1 \text { year post intervention }\end{array}$ & $\begin{array}{l}2.1 \\
(9.3)\end{array}$ & $\begin{array}{l}1.7 \\
(6.4)\end{array}$ & \\
\hline $\begin{array}{l}\text { Within group differences prior to and } \\
\text { post intervention, p-value }\end{array}$ & .830 & .052 & \\
\hline
\end{tabular}

The association between depressive symptoms and changes in healthcare use in patients randomized to iCBT or ODF

The factors associated with change in healthcare use (i.e., outpatient clinic and/or primary care contacts, and/or hospital admissions) the year post intervention compared to the year before are presented for the iCBT and ODF group respectively in Table 6. After adjustments for the other correlates of change in healthcare use, lower PHQ-9 scores in the iCBT group, post intervention demonstrated a significant moderate association (Beta $=.459, p=.047$ ), with a decrease in the number of outpatient clinic and/or primary care contacts. In the ODF group, higher MCS12 scores post intervention had a significant moderate association (Beta $=-.429, p=.045$ ) with a decrease in number of hospital admissions. 
Table 6

Factors impacting healthcare use (outpatient clinic/primary care contacts, and hospital admissions) in patients receiving internet-delivered cognitive behavioural therapy (iCBT) or online discussion forum

(ODF).

\begin{tabular}{|c|c|c|c|c|c|c|c|c|}
\hline \multirow[b]{3}{*}{$\begin{array}{l}\text { Explanatory } \\
\text { variables }\end{array}$} & \multicolumn{4}{|c|}{ iCBT $(n=70)$} & \multicolumn{4}{|c|}{ ODF $(n=68)$} \\
\hline & \multicolumn{2}{|c|}{$\begin{array}{l}\text { Change in } \\
\text { contacts } \\
\text { between years }\end{array}$} & \multicolumn{2}{|c|}{$\begin{array}{l}\text { Change in } \\
\text { admissions between } \\
\text { years }\end{array}$} & \multicolumn{2}{|c|}{$\begin{array}{l}\text { Change in } \\
\text { contacts } \\
\text { between years }\end{array}$} & \multicolumn{2}{|c|}{$\begin{array}{l}\text { Change in } \\
\text { admissions } \\
\text { between years }\end{array}$} \\
\hline & Beta & $\begin{array}{l}\mathrm{p}- \\
\text { value }\end{array}$ & Beta & p-value & Beta & $\begin{array}{l}\text { p- } \\
\text { value }\end{array}$ & Beta & p-value \\
\hline Sex & -.029 & .835 & .104 & .476 & .182 & .193 & .002 & .989 \\
\hline Marital status & .026 & .862 & -.063 & .689 & -.283 & .067 & -.253 & .093 \\
\hline Occupation & -.083 & .602 & .124 & .456 & .009 & .952 & .205 & .165 \\
\hline Financial situation & -.271 & .081 & -.053 & .743 & .003 & .983 & .166 & .224 \\
\hline $\begin{array}{l}\text { Number of co- } \\
\text { morbidities }\end{array}$ & .075 & .597 & -.102 & .490 & .152 & .330 & .051 & .739 \\
\hline $\begin{array}{l}\text { PHQ-9 score post } \\
\text { intervention }\end{array}$ & .459 & .047 & .158 & .507 & -.229 & .304 & -.282 & .197 \\
\hline $\begin{array}{l}\text { PCS12 score post } \\
\text { intervention }\end{array}$ & .015 & .937 & .115 & .576 & -.081 & .745 & -.298 & .226 \\
\hline $\begin{array}{l}\text { MCS12 score post } \\
\text { intervention }\end{array}$ & .181 & .388 & -.085 & .699 & -.288 & .183 & -.429 & .045 \\
\hline $\begin{array}{l}\text { EQ-VAS score post } \\
\text { intervention }\end{array}$ & .272 & .185 & -.018 & .934 & .341 & .169 & .439 & .072 \\
\hline
\end{tabular}

\section{Discussion}

Studies performing health-economic evaluations of iCBT interventions on depression are rare and very few if any such studies have been performed on patients with chronic somatic states. In this study, we aimed to describe and compare the iCBT and ODF groups with regard to healthcare use and to identify factors impacting healthcare use in these groups. We found that both the ICBT and ODF groups had a high level of healthcare use (especially outpatient clinic/primary care contacts) the year prior to the intervention. The year post intervention, the healthcare use had decreased by approximately one third in both groups. However, this was not significantly different between the groups. Interestingly in the iCBT group only, lower levels of depressive symptoms post intervention were associated with a decrease in the number of outpatient clinic and/or primary care contacts.

We found that the use of outpatient services the year prior the intervention (31 for iCBT and 37 for ODF) was in both groups higher than was reported for CVD patients in a previous cross-sectional study (23). In 
that study, patients with myocardial infarction had 10 contacts and patients with Angina Pectoris 17 healthcare contacts. We did not measure depression the year prior the intervention, but it is not uncommon that depression in CVD patients can become chronical since depression seldom is detected and that patients are not offered treatment (8). A possible explanation behind the high use of outpatient services the year prior the intervention in our sample could therefore be due to depression. The association between mental health disorders and increased healthcare use among patients with chronic diseases has been noted in previous research (4-6). It is also known that the addition of depression to CVD carries a higher risk for healthcare use, in particular for those with chronic depression (8). Morrissey (24) found in a population-based study of 791 individuals with CVD that the addition of a non-related comorbidity (such as depression/anxiety) led to a three times higher risk for use of outpatient services, such as general practitioner visits, and 1.5 times higher risk for use of inpatient services. In our study, most of the contacts within outpatient/primary care clinics were to physicians and primary care nurses. Hence, as depression is one of the most important factors associated with increased healthcare use in CVD patients, this indicates a need to optimise the management of depression in these patients. When performing interventions that target depression in CVD patients, Palacios et al. (8) suggested that these should focus the impact on depression and healthcare use in CVD outpatients.

We have previously reported that 9 weeks of iCBT compared to ODF (i.e., an active control group) had significantly better effects on depressive symptoms and HRQoL in CVD outpatients (15). In the present study we reported the effect on healthcare use. The number of admissions was relatively low in both groups, before as well as after the intervention, and it is therefore hard to identify any differences between the groups. The number of hospital admissions was 0.8 in the iCBT and 1.1 in the ODF groups prior the intervention, and the year post intervention this had decreased to 0.6 in both groups. The low number of hospital admission, especially in the iCBT group may also explain why only a significant decrease was detected in the ODF group. We found that both groups had a significant decrease in number of outpatient clinic and/or primary care contacts the year post intervention by approximately $30 \%$, but no differences could be found between the groups (Table 3). The difference between numbers of in- and outpatient service use is mostly due to the structure of the Swedish healthcare system, were primary care serves as the first check point and people are initially referred there for consultation regarding their care needs (25). Suggesting that interventions targeting depressive symptoms in CVD are more likely to have impact on the number of outpatient clinic and/or primary care contacts than the number of hospital admission.

We could not find that iCBT was superior to ODF in decreasing the use of healthcare services. A similar finding was reported in the meta-analysis by Kolovos et al. showing that iCBT compared to control was not more cost-effective (12). Still, the finding that iCBT at first sight does not seem to have any healtheconomic benefits may be related to the design of the control conditions. In our study iCBT was compared to an active control group (i.e. ODF). After completion of ODF, all patients were offered iCBT. This design was due to ethical reasons, and $38 \%$ of them accepted and received iCBT. In the metaanalysis some of the five studies also used more active control approaches such as psychoeducation, care as usual and a self-help booklet or a waiting list and who also received iCBT (12). 
In our study, patients in the control group were involved in a discussion forum that enabled them access to other CVD patients' experiences, tips, and support, and hypothetically also a reduced need of support from healthcare services. Other studies (26) also show that active control approaches have impact on depressive symptoms and makes it harder for iCBT to demonstrate a greater impact on healthcare use. As mentioned, those in the ODF group also received iCBT. This could explain why both iCBT and ODF groups showed a decrease by $30 \%$ in healthcare use. Having in mind that most CVD patients with depression in real life are not detected or receive any treatment, Celano et al. (27) argues that iCBT in CVD patients would lead to health-economic benefits.

We also demonstrated that lower depressive symptoms scores post intervention were associated with a decrease in the number of outpatient clinic and/or primary care contacts, in favour of the iCBT group. This indicates that lower levels of depressive symptoms, that in a significantly higher extent were achieved by the iCBT group compared to ODF (15), resulted in a decrease in outpatient service use. In the ODF group, improved HRQoL as measured by MCS12 scores post intervention was moderately associated with a decrease in number of hospital admissions. This association was not found in the iCBT group. Since impaired HRQoL has been associated with increase in hospital admissions in CVD (28), the improved HRQoL in the ODF group might explain the significant decrease of $45 \%$ in hospital admissions.

Since our control group was an active control and of which one-third also received iCBT post-intervention, we cannot exclude the possibility that iCBT has health-economic benefits and may have reduced the differences between the groups regarding healthcare use. Based on the intervention group including 72 patients, the time consumption for a therapist in the iCBT program was about 13 minutes per patient per week, which sums up to two hours per patient for the nine weeks treatment and to 140 hours for the whole iCBT group. Face-to-face CBT is normally at least 10 sessions/weeks with about 45 minutes per session. The time needed for treating 72 patients would therefore sum up to 540 hours for the whole treatment. By using the Internet to deliver the CBT treatment, the time saving would correspond to about 400 therapist hours. Above this, there are other savings in relation to the patients and society in general

since the treatment can be performed when suitable for the patients without travel expenses to healthcare facilities or lost working hours for therapist appointments. Thus, iCBT for depressive symptoms in CVD seems to be cost-saving, but in order to draw the correct conclusions, a cost-effectiveness analysis needs to be carried out.

\section{Limitations}

The study was primarily designed to improve depressive symptoms and hence not to measure differences in healthcare use. Therefore, these results should be interpreted with caution. To detect a significant difference between the groups with a power of $80 \%$ based on our values regarding primary care contacts, would have required a sample size of 567 patients per group. It would have been informative to know more about the reason (e.g. CVD, mental health) for the healthcare use, but our registers did not include such information. To gain such information, scrutinizing patients' medical 
records would have been needed, which would have required a great amount of resources. Despite these limitations, we believe that the results provide important information since there is a lack of studies performing health-economic analyses of iCBT in CVD patients with depressive symptoms.

\section{Conclusions}

We found high levels of outpatient healthcare use in the iCBT and ODF groups the year prior to the intervention. One year after the intervention, outpatient healthcare use had decreased by one third in both groups. Despite that lower levels of depressive symptoms post intervention in the iCBT group were associated with a decrease in outpatient healthcare use, iCBT was not superior compared to ODF in decreasing healthcare use.

\section{Abbreviations}

CVD

cardiovascular disease; EQ-VAS:EuroQol Visual Analogue Scale; HRQoL:health-related quality of life; iCBT:Internet-based cognitive behavioural therapy; MCS:mental component score; ODF:online discussion forum; PHQ-9:Patient Health Questionnaire-9; PCS:physical component score; RCT:randomized controlled trial; SF-12:Short Form 12; SF-36:Short Form-36.

\section{Declarations}

\section{Ethical approval and consent to participate}

The study was carried out in accordance with the Declaration of Helsinki and was approved by the Regional Ethical Review Board in Linköping, Sweden (ref. no. 2011/166-31). The primary study was registered at ClinicalTrials.gov (NCT02778074). Participants signed an informed consent before study inclusion.

\section{Consent for publication}

Not applicable

\section{Availability of data and materials}

The datasets used and/or analyzed during the current study are available from the corresponding author on reasonable request.

\section{Competing interests}


The authors declare that they have no competing interests.

\section{Funding/Acknowledgements}

The Swedish Research Council (2015-02600) and the Medical Research of Southeast Sweden (FORSS848511 ) funded the study but had no involvement in any part of the study.

\section{Authors' contributions}

GM, JL, GA and PJ contributed to the conception and design of the study. GM and JL collected and processed the data. GM, JL and PJ performed the statistical analyses. GM, JL, GA, MW and PJ contributed to the analysis and interpretation of the data and drafting of the manuscript.

\section{References}

1. Hare DL, Toukhsati SR, Johansson P, Jaarsma T. Depression and cardiovascular disease: a clinical review. Eur Heart J. 2014;35(21):1365-72.

2. Johansson P, Lesman-Leegte I, Lundgren J, Hillege HL, Hoes A, Sanderman R, et al. Time-course of depressive symptoms in patients with heart failure. J Psychosom Res. 2013;74(3):238-43.

3. Davydow DS, Fenger-Grøn M, Ribe AR, Pedersen HS, Prior A, Vedsted P, et al. Depression and risk of hospitalisations and rehospitalisations for ambulatory care-sensitive conditions in Denmark: a population-based cohort study. BMJ Open. 2015;5(12):e009878.

4. Koopmans GT, Donker MC, Rutten FH. Common mental disorders and use of general health services: a review of the literature on population-based studies. Acta Psychiatr Scand. 2005;111(5):341-50.

5. Lacruz ME, Emeny RT, Haefner S, Zimmermann AK, Linkohr B, Holle R, et al. Relation between depressed mood, somatic comorbidities and health service utilisation in older adults: results from the KORA-Age study. Age Ageing. 2012;41(2):183-90.

6. Sporinova B, Manns B, Tonelli M, Hemmelgarn B, MacMaster F, Mitchell N, et al. Association of Mental Health Disorders With Health Care Utilization and Costs Among Adults With Chronic Disease. JAMA Netw Open. 2019;2(8):e199910.

7. Szpakowski N, Qiu F, Masih S, Kurdyak P, Wijeysundera HC. Economic Impact of Subsequent Depression in Patients With a New Diagnosis of Stable Angina: A Population-Based Study. J Am Heart Assoc. 2017;6(10).

8. Palacios J, Khondoker M, Mann A, Tylee A, Hotopf M. Depression and anxiety symptom trajectories in coronary heart disease: Associations with measures of disability and impact on 3-year health care costs. J Psychosom Res. 2018;104:1-8.

9. Müller-Tasch T, Peters-Klimm F, Schellberg D, Holzapfel N, Barth A, Jünger J, et al. Depression is a major determinant of quality of life in patients with chronic systolic heart failure in general practice. 
J Card Fail. 2007;13(10):818-24.

10. Andrews G, Basu A, Cuijpers P, Craske MG, McEvoy P, English CL, et al. Computer therapy for the anxiety and depression disorders is effective, acceptable and practical health care: An updated metaanalysis. J Anxiety Disord. 2018;55:70-8.

11. Donker T, Blankers M, Hedman E, Ljótsson B, Petrie K, Christensen H. Economic evaluations of Internet interventions for mental health: a systematic review. Psychol Med. 2015;45(16):3357-76.

12. Kolovos S, van Dongen JM, Riper H, Buntrock C, Cuijpers P, Ebert DD, et al. Cost effectiveness of guided Internet-based interventions for depression in comparison with control conditions: An individual-participant data meta-analysis. Depress Anxiety. 2018;35(3):209-19.

13. Reavell J, Hopkinson M, Clarkesmith D, Lane DA. Effectiveness of Cognitive Behavioral Therapy for Depression and Anxiety in Patients With Cardiovascular Disease: A Systematic Review and MetaAnalysis. Psychosom Med. 2018;80(8):742-53.

14. McCombie A, Gearry R, Andrews J, Mikocka-Walus A, Mulder R. Computerised cognitive behavioural therapy for psychological distress in patients with physical illnesses: a systematic review. J Clin Psychol Med Settings. 2015;22(1):20-44.

15. Johansson $P$, Westas $M$, Andersson G, Alehagen U, Broström A, Jaarsma T, et al. An Internet-Based Cognitive Behavioral Therapy Program Adapted to Patients With Cardiovascular Disease and Depression: Randomized Controlled Trial. JMIR Ment Health. 2019;6(10):e14648.

16. Spitzer RL, Kroenke K, Williams JB. Validation and utility of a self-report version of PRIME-MD: the PHQ primary care study. Primary Care Evaluation of Mental Disorders. Patient Health Questionnaire. Jama. 1999;282(18):1737-44.

17. Kroenke K, Spitzer RL, Williams JB. The PHQ-9: validity of a brief depression severity measure. Journal of general internal medicine. 2001;16(9):606-13.

18. Hammash MH, Hall LA, Lennie TA, Heo S, Chung ML, Lee KS, et al. Psychometrics of the PHQ-9 as a measure of depressive symptoms in patients with heart failure. Eur $\mathrm{J}$ Cardiovasc Nurs. 2013;12(5):446-53.

19. Erbe D, Eichert HC, Rietz C, Ebert D. Interformat reliability of the patient health questionnaire: Validation of the computerized version of the PHQ-9. Internet Interv. 2016;5:1-4.

20. Ware J, Jr., Kosinski M, Keller SD. A 12-Item Short-Form Health Survey: construction of scales and preliminary tests of reliability and validity. Medical care. 1996;34(3):220-33.

21. Brooks RG, Jendteg S, Lindgren B, Persson U, Björk S. EuroQol: health-related quality of life measurement. Results of the Swedish questionnaire exercise. Health Policy. 1991;18(1):37-48.

22. Müller-Nordhorn J, Roll S, Willich SN. Comparison of the short form (SF)-12 health status instrument with the SF-36 in patients with coronary heart disease. Heart. 2004;90(5):523-7.

23. Mourad G, Jaarsma T, Hallert C, Stromberg A. Depressive symptoms and healthcare utilization in patients with noncardiac chest pain compared to patients with ischemic heart disease. Heart \& lung: the journal of critical care. 2012;41(5):446-55. 
24. Morrissey K. Comorbidity and healthcare use for individuals with CVD in the Ireland: a crosssectional, population-based study. BMJ Open. 2019;9(1):e025305.

25. Joumard I, Organisation for Economic Co-operation and D. Health care systems: efficiency and policy settings. Paris: Oecd; 2010. 207 p.

26. Enck P, Zipfel S. Placebo Effects in Psychotherapy: A Framework. Front Psychiatry. 2019;10:456.

27. Celano CM, Villegas AC, Albanese AM, Gaggin HK, Huffman JC. Depression and Anxiety in Heart Failure: A Review. Harv Rev Psychiatry. 2018;26(4):175-84.

28. Pocock S, Brieger DB, Owen R, Chen J, Cohen MG, Goodman S, et al. Health-related quality of life 1-3 years post-myocardial infarction: its impact on prognosis. Open heart. 2021;8(1).

\section{Figures}

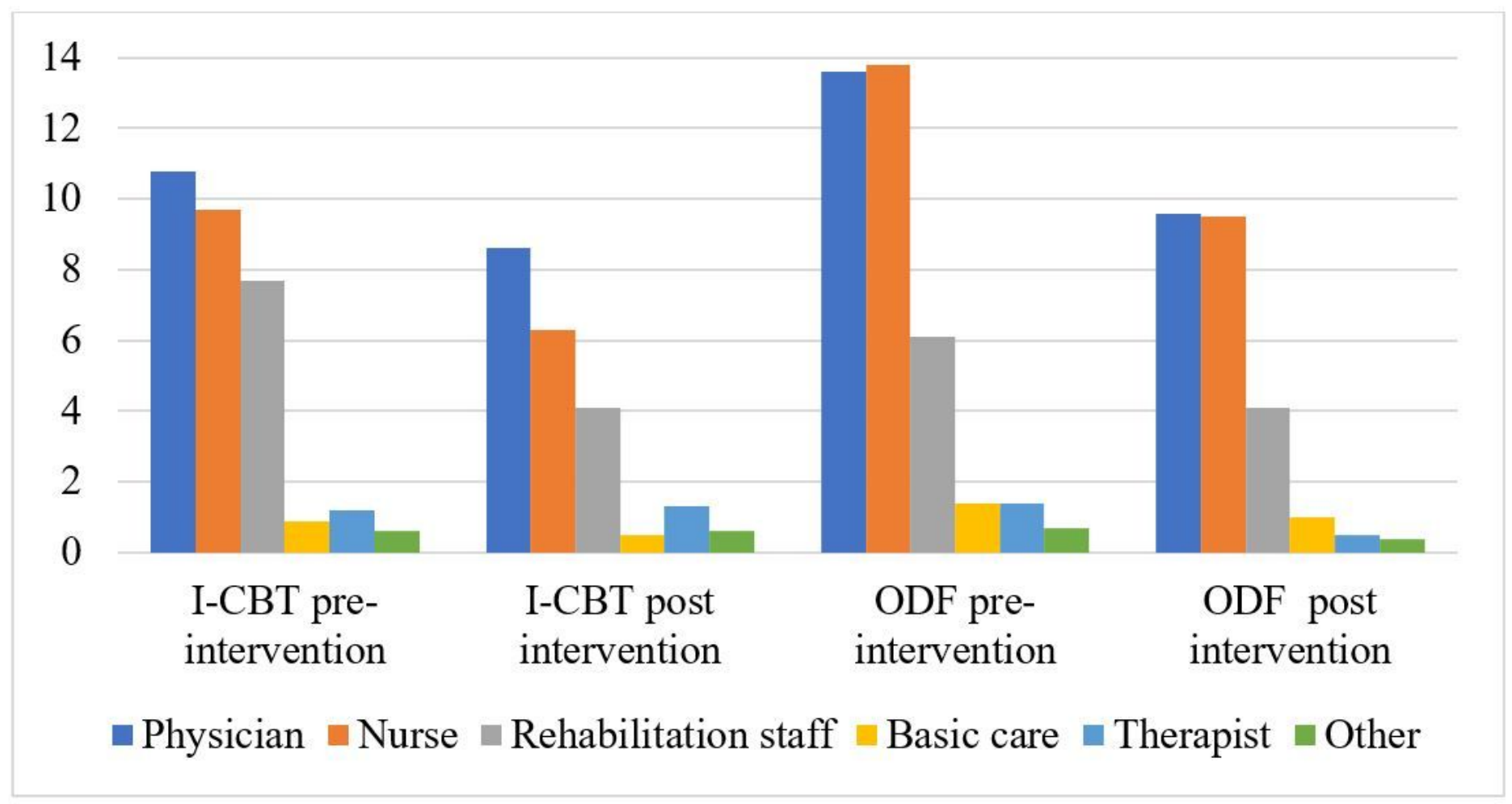

\section{Figure 1}

Type of contact within outpatient clinic and/or primary care contacts in patients randomized to internetdelivered cognitive behavioural therapy (iCBT) or online discussion forum (ODF) one year prior to and one year post intervention. No significant differences were found between the groups.

\section{Supplementary Files}

This is a list of supplementary files associated with this preprint. Click to download. 
- ConsortchecklisthealthcareuseinCVDpatients.docx

- HighlightshealthcareuseinCVDpatients.docx 